\title{
Teaching Analysis in the Principles of Chemical Engineering for Environmental Engineering
}

\author{
Sun Zhiguo \\ School of Environmental and Materials Engineering \\ Shanghai Second Polytechnic University \\ Shanghai, P. R. China \\ zgsun@sspu.edu.cn
}

\author{
Xie Hongyong \\ School of Environmental and Materials Engineering \\ Shanghai Second Polytechnic University \\ Shanghai, P. R. China
}

\author{
Zhang Li \\ School of Environmental and Materials Engineering \\ Shanghai Second Polytechnic University \\ Shanghai, P. R. China
}

\begin{abstract}
According to the cultivation aims and characteristics of environmental engineering in major of environmental engineering, this article discusses the teaching reform from some new perspectives, such as the teaching contents and methods, arousing the students' interest and thinking, promoting teaching by scientific research, and cultivation of engineering quality. It will improve the teaching of principles of chemical engineering for environmental engineering major.
\end{abstract}

Keywords-Environmental engineering; the principles of chemical engineering; teaching reform;teaching method

\section{INTRODUCTION}

Principles of chemical engineering are an important basic course in major of Environmental Engineering. In order to research the basic theory of chemical unit operation structure of typical equipment and calculation of process dimension, the unit operation is taken as the content of this course. And the mainline of this course is to deliver the process principles and research methods. Principles of chemical engineering cover a large area. It is also informative with strong application and link the theory with practice. Principles of chemical engineering are a course which has a strong practicality and engineering quality. It serves as the link between the basic course and specialized course for the students who are major in environmental engineering. It also acts as the introductory course for the transition of nature science to engineering science. This article gives the suggestions according to the actual situations of environmental engineering in our school and the past experience of teaching reform in this course. ${ }^{[1]}$

\section{AdJust ThE TEACHING CONTENT ACCORDING TO THE CHARACTERISTICS OF ENVIRONMENTAL ENGINEERING}

Unit operations in environmental engineering is different

The authors gratefully acknowledge financial support by the Innovation Program of Shanghai Municipal Education Commission (No.13YZ130), and Cultivate discipline fund of Shanghai Second Polytechnic University (No.XXKPY1303). from the others, so in the premise of the short term, the course must revolve the training objective tightly and adjust the teaching content to focus on one point so that a systematic and integration content can be founded which fits this major. The primary task for training talent person in environmental engineering is to teach Water pollution control and air pollution control. The core of this task is to separate and remove the pollutants from waste water and exhaust air. What we should do is to deal with the system consists of the mixture of gas-gas gas-solid gas-gas liquid-solid and liquid-liquid. According to the position and training objectives in environmental engineering as well as the characteristic of environmental engineering technology industry, we teach some courses such as adsorption which is closely related to environmental engineering besides teaching fluid flow, heat transfer, absorption and distillation. We also considered that Principles of Chemical Engineering in environmental engineering should pay more attention on application, so some part of certain chapter is reduced and mathematical derivation of some formulas is simplified, thus, we can focus on the conclusion applications and conditions of use. After those integrations, Principles of Chemical Engineering in environmental engineering can become more adapt to teaching content for 48 teaching hours. ${ }^{[2]}$

\section{COMBINED WITH PRACTICAL PROBLEMS AND AROUSE STUDENTS' INTERESTS}

Unit operations and principles in this course often make the students feel abstract and difficult to grasp. Therefore, during the teaching process, we should start from the common phenomenon which is closely related to actual production, and then raise some questions which are enlightening and value for thinking. This can leads to the new knowledge, as well can stimulate students' interest, promote their positive thinking, and promote students' understanding of the content. For 
example, when you are going to teach heat transfer, some questions can be asked before teaching. The questions may like: How many kinds of heat exchangers are there in our daily life? From the answers given by the students, contents need to be taught such as mode of heat transfer, characteristic of heat transfer and its' factors can be introduced. This method can make the students focus on study quickly and can also arouse the enthusiasm of students to learn a new lesson thus forming a good learning atmosphere. During the teaching process, set a certain amount and a certain difficulty questions such as: Why the pot liner should be evacuated? Why the surface should be silvered? The purpose of those questions is to encourage the students to think initiatively and also mobilize the enthusiasm of the students' thinking. It may also keep various forms of communication between thinking and learning. So that students can think synchronously with the teachers even think ahead of the teachers. This can help to cultivate the ability of solving problems independently and stimulate student interest and initiative. [3]

\section{INTRODUCE FRONTIER SCIENCE AND TECHNOLOGY TO PROMOTE TEACHING}

In teaching process, besides teaching students to understand the traditional unit operations, we should also pay attention to the introduction of frontier science and technology as well as professional developments, so as to stimulate the curiosity of students, expanding students' knowledge. Research activities can enrich the teaching content. During the teaching process the organic combination of knowledge and frontier science and technology is an important aspect to show the teaching quality. Nowadays research results coming thick and fast, new contents and ideas should be added in the text books in time. We hold the opinion that teaching should be closely related to research, we should enrich the teaching content with new knowledge and new scientific results continuously. For example when we are going to teach absorb, we can introduce flue gas desulfurization and denitrification technology to the students briefly, this can enable the students to understand the actual power plant flue gas treatment processes and the development of frontier technologies. As teachers, we have to search a large amount of literature, understand the development of frontier science and technology and expand our knowledge. The knowledge can be enriched into the lectures, so that the organic combination of knowledge and frontier science and technology can be accomplished. Teachers can put their own scientific research into daily teaching to make the students acquire new knowledge and understand latest academic development. Teachers can put their research result into teaching content as teaching case. They can also use their published research paper as extracurricular reading materials. All these may enable the students to deepen their understanding of textbook theory and practical application of concepts. ${ }^{[4]}$

\section{INCREASE DISCUSSION, STIMULATE THINKING}

The teaching methods which simply use teacher and textbook as the main line cannot meet today's needs to cultivate students' abilities. Traditional teaching methods often make the students cramming into a passive position, which hindering the students' initiative and the development of innovative thinking. One of the main purposes of the course reformation is to change the teacher-centered teaching model and establish a new kind of teaching model which not only unleash the leading role of teachers but also reflect the students' understanding. Classroom discussion is a good model. The students learn and discuss a certain topic under the guidance of teachers then find questions discuss questions and finally solve the questions. It can active the classroom atmosphere, mobilize the enthusiasm of students and cultivate self-study ability.

\section{IMPROVE TEACHING EFFICIENCY AND VENUE IN THE LABORATORY CLASSROOM}

Principles of Chemical Engineering involves a large number of complex chemical equipment, it has complex device structures, operating principles, and processes. How to let students acquire more knowledge in the limited time still remains a problem. We may try to teach them in the laboratory directly. For example when we are going to teach fluid transport machinery we can use the fans and pumps in the laboratory to make the students know their structures and working principles. It is much better than just simply explain their principles by the pictures in the classroom. ${ }^{[5]}$

\section{BLACKBOARD WRITING WITH MULTIMEDIA TEACHING}

Multimedia teaching is vivid and intuitive. It can make up students' difficulties which caused by the lack of practical experience. Considering that multimedia is consists of audio and video, it is also Illustrations, static and dynamic binding. There is no doubt that it can demonstrate the internal structure of the unit device, the process principle, and operation of the device vividly. Owing to that, multimedia has the ability to visualize complex structures and simplistic abstractions. It can also lay the foundation for building a link between device structures, liquidity mixed state and operational parameters in students' brains. Through multimedia teaching, the use of flash animation and many other methods have solved the longstanding traditional problem in teaching and have improved the teaching quality. In addition we can show our own teaching features by using the flexibility and convenience of multimedia, thanks to that, the students may closely follow the class progress to understand, think and acquire the knowledge. Therefore, we can improve the teaching efficiency of shorthour courses. Media and writing on the blackboard is teaching methods which complement each other, so we can't overuse multimedia and give up writing on the blackboard completely. Since the playback speed of PPT is too fast, so when we are going to explain some certain exercises, writing on the blackboard maybe the best choice. This method is much easier for students to understand the problem solving process step by step. [6]

\section{ACCORDING TO THE CHARACTERISTICS OF MAJOR, ADD AND DELETE EXPERIMENTAL CONTENT}

Compared with the general basic experiment, the experiment in Principles of Chemical Engineering has engineering features. Every experiment is just like a unit 
operation in chemical production, through these experiments can build some engineering concepts. As for the students major in science and technology, they can learn principles and testing methods more actual and effective. They can also find the link between real process and the mathematical model describing the process. So this is a very important practical course. However the experiment in Principles of Chemical Engineering covers a large area and interpenetration with various disciplines, the knowledge of various disciplines on the chemical unit operations also have different needs. Thus, we cannot use the same pattern the same content to generalize different majors. we should make a choice based on the majors. We should set experimental teaching content according to the characteristics of environmental engineering selectively and targeted. We should focus on the associated experiment and delete the experiment which has few relations. This makes chemical engineering principle experiment closer to practical teaching, so that to mobilize the enthusiasm of students, also lay foundation for professional development and innovation in the future. For example, distillation and drying unit operation experiments is almost never used in the field of environmental engineering so it is recommended to delete those two experiments in a limited amount of hours. In addition, the adsorption separation is widely used in the field of environmental protection, such as flue gas $\mathrm{SO}_{2}, \mathrm{NO}_{x}$ governance, as well as wastewater treatment and drinking water production. Therefore adsorption separation technology is a very useful technique, especially for environmental emissions and wastewater treatment. So it is necessary to create adsorption unit operations experiment in environmental engineering. [7]

\section{CONCLUSIONS}

Principles of Chemical Engineering for environmental engineering must revolve the training objective tightly, the theory and experiment in this course should be reasonable adjusted. It should also combine with practical problems so as to stimulate students' interests and thinking, and cultivate students' engineering quality at the same time. Frontier science and technology should be introduced into actual teaching, and multimedia should be used. We will make reformation in teaching methods and teaching tools continuously to meet the community's quality profession requirements in environmental engineering.

\section{REFERENCES}

[1] Hu Hongbo, Wang Wei, Peng Huasong, et al. Teaching Reform in the Principles of Chemical Engineering for Bioengineering $[\mathrm{J}]$. Higher Education in Chemical Engineering, 2013, Vol.30, pp.42-44.

[2] Qian Yong, Wang Yanlin, Zhao Xin. Discussion on Teaching Reform of Principles of Chemical Engineering with Limited Less Class Time[J].Guangdong Chemical Industry, 2009, Vol.36, pp.190-191.

[3] Luo Zhijun, Ai Fengxiang, Wu Xiangyang. Experiences in Teaching of Principle of Chemical Engineering with Limited Less Class Time[J]. Examination Weekly, 2012, No. 46, pp.143.

[4] Xu Ke, Niu Junling, Liu Juntan, et al. Teaching Reform in the Principles of Chemical Engineering for Environmental Engineering [J].Science and Technology Innovation Herald, 2009, No.34, pp.128.

[5] Song Chengfang, Luo Xiping, Zhou Shan. Experimental Teaching Reform in the Principles of Chemical for Environmental Engineering Majors[J]. Guangzhou Chemical Industry, 2012, Vol.40, pp.143-144.

[6] Tong Hanqing, Yu Xiang. Dimensional Teaching Mode of Principles of Chemical Engineering Based on Cultivation of Applied Talents[J]. Value Engineering, 2012, 31(7):213-215.

[7] Xu Weixiu. Thinking of Cultivation of Engineering Quality in the Course of Principles of Chemical Engineering[J]. Vocational \& Technical Education Forum, 2004, (30):44-45. 